\title{
Optimizing Multiple Immunostaining of Neural Tissue
}

\author{
Araceli Diez-Fraile ${ }^{1}$, Nico Van Hecke ${ }^{1}$, \\ Christopher J. Guérin ${ }^{2,3}$ and Katharina D'Herde ${ }^{1}$ \\ ${ }^{1}$ Department of Basic Medical Sciences, Ghent University, Ghent \\ ${ }^{2}$ Department for Molecular Biomedical Research, VIB, Ghent \\ ${ }^{3}$ Department of Biomedical Molecular Biology, Ghent University, Ghent \\ Belgium
}

\section{Introduction}

This chapter will discuss the optimization of a multiple immunostaining method for studying the distribution of calcium binding proteins in neural tissue. We discuss the different possibilities for brain collection and tissue preservation. Then we present a basic protocol for a multicolor immunostaining technique.

Interference from autofluorescence is one of the major problems in immunofluorescence analysis of neural tissue. This difficulty is experienced even with the use of laser-scanning microscopy, which can eliminate out of focus light but not the undesirable tissue-specific autofluorescence that is in focus. Therefore, we will center our discussion on different strategies to minimize neural tissue autofluorescence. The two greatest sources of autofluorescence discussed here are those induced by aldehyde fixation and by the fluorescent pigment lipofuscin, which accumulates with age in the cytoplasm of cells of the central nervous system. Finally, it is important to determine whether any treatments used to minimize autofluorescence might quench specific fluorescent compounds used to label the proteins of interest. We present the results of multi-label fluorescence immunostaining of cryostat sections of $20 \mu \mathrm{m}$ of the human inferior colliculus. We conclude that the use of chemical agents to reduce autofluorescence and quench lipofuscin-specific fluorescence helps to maximize the fluorescent signal-to-noise ratio in immunocytochemical studies of fixed neural tissues.

\section{Antigen preservation of human brain material}

Preservation of antigens in brain is one of the major methodological problems in the immunohistochemical studies of this tissue. Various premortem events have a negative effect on antigen preservation in human brain tissue, such as prolonged agonal state, hypoxia, acidosis, fever and seizures. Factors related to postmortem events are the time between death and fixation (postmortem delay), temperature variations in cadaver storage, freshness and composition of the fixative solutions. 
Postmortem delay is the most important contributor to the quality difference of immunostained neural tissues between experimentally controlled animal models and human (Hilbig et al., 2004). Indeed, optimal protocols for rapidly fixing central nervous tissue, such as intravascular infusion of fixative into deeply anesthetized animals (Selever et al., 2011), are essential for prevention of enzymatic degradation and antigen loss (Martin \& O'Callaghan, 1995). However, human tissues are usually obtained only several hours after death. Fresh human brain tissue is sometimes obtained during surgery, but such tissue is usually pathologically altered and cannot be used to draw conclusions about normal physiology. Brain banks remain the best source of high quality postmortem human brain tissue for neuropathological studies and related research (McKee, 1999; Waldvogel et al., 2006; Ravid \& Grinberg, 2008; Waldvogel et al., 2008).

For qualitative immunohistochemical analysis, a postmortem delay longer than one day is usually acceptable, but two crucial controls are needed if protein expression levels are to be estimated from immunofluorescence results. Because different proteins degrade at different rates following death (De Groot et al., 1995; Fodor et al., 2002; Hilbig et al., 2004) it is advised to biochemically assess the degredation profile of the antigen(s) of interest prior to immunochemical studies. Indeed, different antigens are affected differently by postmortem catabolic processes (De Groot et al., 1995; Fodor et al., 2002; Hilbig et al., 2004). Second, the specimens must be rigorously matched, e.g., for age, sex, postmortem delay and fixation time.

The most common method for preserving antigen for fluorescence microscopy is immersion in cross-linking agents, such as formaldehyde and glutaraldehyde. In general, $4 \%$ formaldehyde in PBS ( $\mathrm{pH}$ 7.4) made from freshly depolymerized paraformaldehyde is preferred, because treatment with glutaraldehyde may mask amine-containing epitopes, making immunostaining impossible (Willingham, 1999). It is sufficient to incubate small tissue pieces in the fixative overnight at $4^{\circ} \mathrm{C}$. For minimal effects on antibody binding, brain material should be fixed as short a time as possible consistent with good preservation. Fixation for not more than two weeks with refreshment of the fixative every third day has been shown to be successful in immunohistochemical studies (Romijn et al., 1999). Freshly made paraformaldehyde induces a lower background autofluorescence than glutaraldehyde or pre-prepared formalin. How fixative-induced autofluorescence can be reduced is the subject of section 6.1.

\section{Storage and sectioning of tissue}

Cryoprotection is used to prevent freezing artifacts and loss of tissue architecture. Once properly fixed, the brain tissue is immersed in a graded series of sucrose solutions $(10 \%$, $20 \%$ and $30 \%$ in PBS pH 7.4) at $4^{\circ} \mathrm{C}$, until the tissue sinks to the bottom of the container. The sucrose acts as a partial dehydrating substance that protects the tissue against freezing artifacts caused by ice crystal formation when the tissue is frozen (Tokuyasu, 1973). Morphology and immunoreactivity are generally preserved for up to six months when the brain tissue is stored at $4^{\circ} \mathrm{C}$ in buffered $30 \%$ sucrose (supplemented with $0.05 \% \mathrm{NaN}_{3}$ to prevent growth of bacteria) (Romijn et al., 1999). For longer-term storage, freezing in a 30\% sucrose solution in PBS at $-80^{\circ} \mathrm{C}$ has been shown to reasonably preserve the hypothalamus and to cause only minimal freeze artifacts (Romijn et al., 1999). Gathering even a small number of human brain tissue samples usually takes weeks or months. Therefore, to 
perform a reliable, comparative immunocytochemical study, the brain tissue usually needs to be stored frozen.

Before sectioning, the embedded tissue blocks are equilibrated at $-20^{\circ} \mathrm{C}$ for at least one hour. Section thickness is important. Sections that are too thin may be very fragile and tear when handled in long protocols, whereas thick sections have a higher intensity of autofluorescence (Del Castillo et al., 1989). After sectioning, the tissues are rehydrated for at least 40 minutes in TBS or PBS buffer ( $\mathrm{pH} 7.4$ ) before further treatment. Rehydration is done on floating tissue sections or on sections adhered to coated slides.

\section{Multi-label fluorescence immunostaining}

Several antigens can be simultaneously detected in the same tissue section by incubating unconjugated primary antibodies of different origin, followed by labeling with fluorophoreconjugated secondary antibodies against the primary antibodies. This strategy can be more sensitive than directly labeled primary antibodies due to signal amplification through multiple secondary antibody reactions with different antigenic sites on the primary antibody. Higher signal-to-noise ratios can also be achieved through the use of new generation fluorophores such as AlexaFluor and Dylight, which are brighter and more photostable than their older counterparts (e.g. FITC, TRITC). Various controls should be run to verify the specificity of the antibodies in order to avoid false-positive results due to nonspecific binding or to recognition of epitopes shared by different molecules. Negative controls should include incubation in non-immune mouse IgG or normal rabbit serum instead of the primary antibody, omission of the primary and/or the secondary antibody and pre-adsorption of the antibody with an excess of purified antigen. Controls can also be sections from other tissues or brain regions known to contain (positive control) or to lack (negative control) the protein of interest. Staining is deemed specific only if both negative and positive controls give unequivocal results. Neurons and other cells present in neural tissue can also be visualized by combining the previous protocol with neuron specific reagents such as Neurotrace ${ }^{\mathrm{TM}}$ fluorescent Nissl stains and DAPI or Hoechst 33258 DNA stains.

When primary antibodies from different species are not available, methods for multiple immunolabeling with primary antibodies originating from the same host species can be used (Buchwalow et al., 2005; Frisch et al., 2011). Moreover, when greater sensitivity is required amplification methods such as the tyramide signal amplification method or avidinbiotin complexing can be employed (Brouns et al., 2002; Tóth \& Mezey, 2007; Bratthauer, 2010).

In Section 2 we have mentioned the importance of using rigorously matching brains in quantitative studies. In addition, the matching samples need to be processed and evaluated simultaneously using the same solutions. In this way, large differences in the intensity between conditions can be shown. However, the results should be confirmed by truly quantitative methods, such as western blotting technique.

\section{Confocal laser scanning microscopy}

The use of confocal fluorescence microscopy to analyze multiple immunolabeled sections has several advantages over conventional methods. First, confocal microscopy can filter out-of- 
focus light to yield sharp, high-contrast images of thick samples. In addition, by collecting 2-D images from different planes in the tissue, a volume of tissue can be reconstructed in 3-D. Another advantage is that since most systems are equipped with multiple lasers of different wavelengths, they can excite a set of fluorescent probes spanning nearly the full range of visible wavelengths, allowing multiprobe imaging of the specimen (Dailey et al., 1999).

Nevertheless, confocal microscopy will not eliminate non-specific background fluorescence, which is the main problem in the immunohistochemical analysis of adult human neural tissue. Indeed, imaging of neural tissue is usually not satisfactory due to the broad emission spectrum of the autofluorescence which can overlap the specific fluorescent labels. An example of autofluorescence in a human brain tissue sample is shown in Figure 1. Therefore, the protocol should be optimized for multiple fluorescent immunolabeling by treating the samples as described in section 6 in order to improve the visualization of the fluorochromes of interest.

\section{Non-specific background fluorescence or autofluorescence}

Autofluorescence is a common problem in aged human brain tissue and when present, it decreases the signal-to-noise ratio of specific labeling. The main causes of autofluorescence in the central nervous system are artifacts due to fixation and endogenous causes such as the fluorescent pigment lipofuscin, which accumulates as cells age.

\subsection{Evaluation of fixative-induced fluorescence}

The most common method to fix tissue for fluorescence microscopy is immersion in crosslinking agents, such as formaldehyde and glutaraldehyde. The aldehydes form covalent bonds between adjacent amine-containing groups through a Schiff acid-base reaction, which leads to formation of methylene bridges and other types of links (Collins \& Goldsmith, 1981; Fox et al., 1985). However, unreacted aldehyde groups fluoresce efficiently at the same wavelengths similar to the fluorescent probes employed for immunofluorescence assays. Since glutaraldehyde possesses two functional groups per molecule while formaldehyde has only one, background autofluorescence is more problematic for tissues fixed with glutaraldehyde. To keep the background autofluorescence as low as possible in immunocytochemistry, the preferred buffer for fixing tissue is $4 \%$ formaldehyde in PBS (pH 7.4) made from freshly depolymerized paraformaldehyde. Fixative-related autofluorescence is visualized as fairly uniform broad spectrum fluorescence and may be brighter in some cells than in others, depending on the presence of biogenic amines (Clancy \& Cauller, 1998).

Fixative-induced autofluorescence may be circumvented by quenching unreacted aldehydes. A common method is to pretreat fixed sections with reducing agents, such as freshly prepared sodium borohydride $\left(\mathrm{NaBH}_{4} ; 1 \% \mathrm{w} / \mathrm{v}\right)$ in PBS for $10-20 \mathrm{~min}$ at $44^{\circ} \mathrm{C}$ (Willingham 1983; Beisker et al., 1987; Tagliaferro et al., 1997; Figure 2) to reduce free aldehyde groups to alcohols. Care should be taken when using $\mathrm{NaBH}_{4}$ solution because it is very caustic and can cause explosions due to release of hydrogen. Alternatively, fixed sections may be treated with exogenous amine-containing reagents, such as: $50 \mathrm{mM} \mathrm{NH}_{4} \mathrm{Cl}$ in PBS for 5-10 min, or in 100-300 mM glycine in Tris buffer $\mathrm{pH} 7.4$ or PBS for $1-2 \mathrm{~h}$ at $4^{\circ} \mathrm{C}$ (Callis 2010; Ngwenya et al., 2005). The best method should be determined empirically. These techniques can be used alone or sequentially. If the tissue is fragile, the glycine method is advised. 

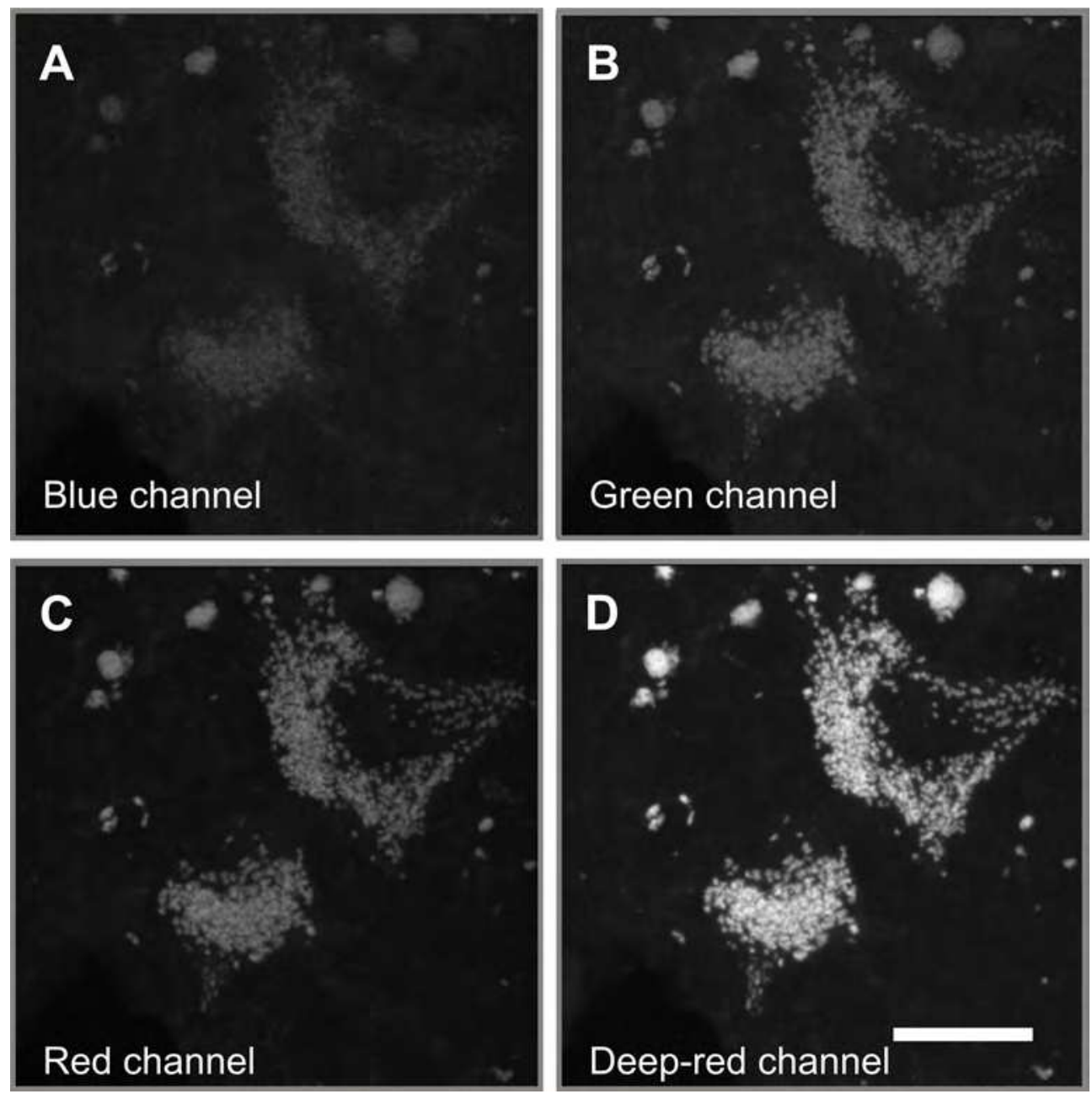

Fig. 1. Punctate autofluorescent structures in a $20-\mu \mathrm{m}$ sagittal section from the human inferior colliculus exposed to the same laser power for the blue (A), green (B), red (C) and deep-red (D) channels. The lipofuscin-related autofluorescence is less visible in the blue channel and strongest in the deep-red channel. The wide overlap in the blue, green, red and deep-red channels supports previous studies showing that lipofuscin has broad spectral emission (Kikugawa et al., 1997; Schnell et al., 1999; Zhang et al., 2010). Magnification =63x; scale bar $=20 \mu \mathrm{m}$ 

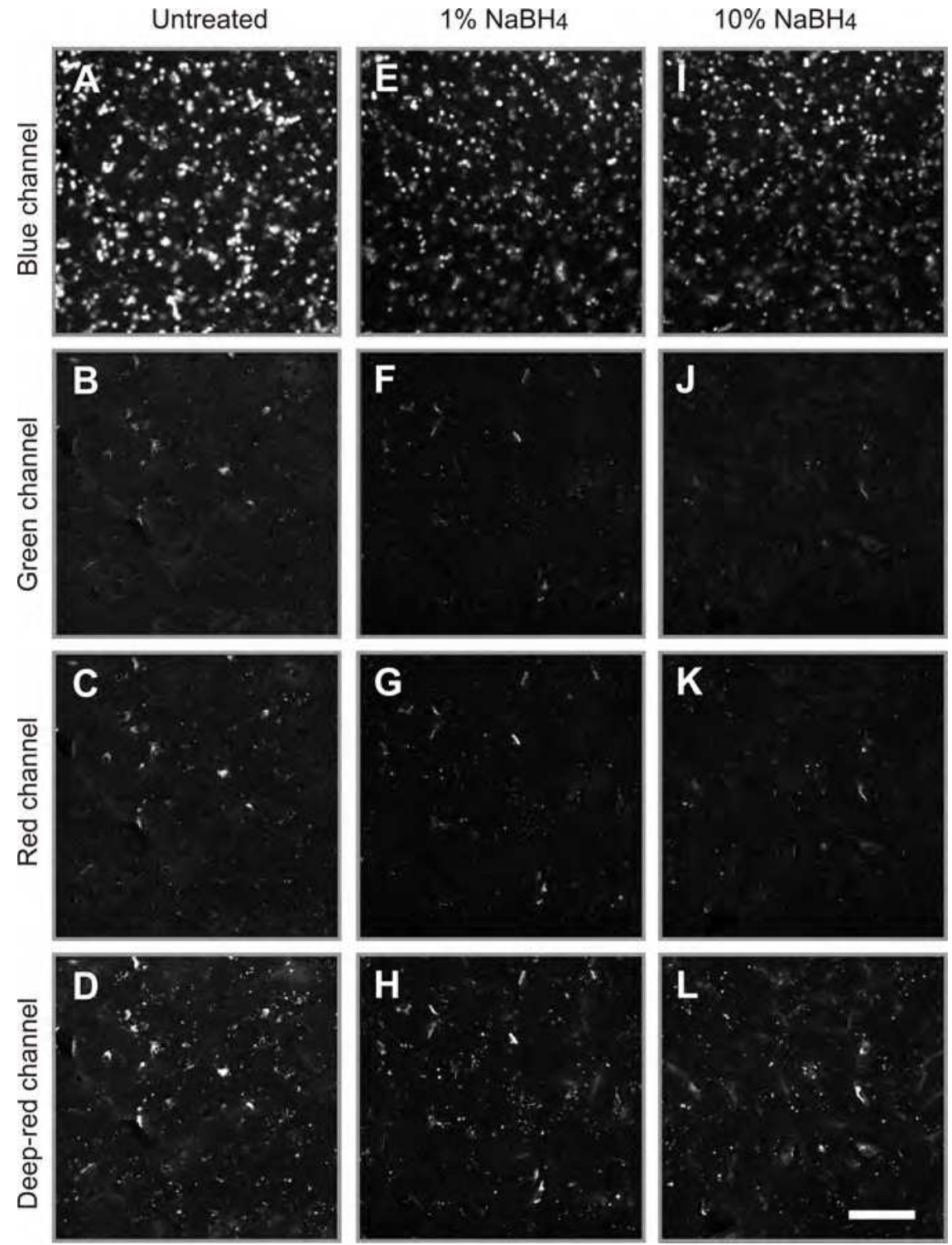

Fig. 2. Effect of incubation under control conditions (A-D), 1\% (E-H) or 10\% sodium borohydride (I-L) on the background fluorescence in $20-\mu \mathrm{m}$ consecutive sections of the human inferior colliculus stained with DAPI and visualized in the blue (A, E, I), green $(\mathrm{B}, \mathrm{F}, \mathrm{J})$, red $(\mathrm{C}, \mathrm{G}, \mathrm{K})$, and deep-red $(\mathrm{D}, \mathrm{H}, \mathrm{L})$ channels by confocal microscopy. Incubation in $\mathrm{NaBH}_{4}$ resulted in a small decrease of the background autofluorescence in each channel, indicating that the un-reduced aldehydes induced by tissue fixation (4\% paraformaldehyde in PBS pH 7.4 for two weeks at $4^{\circ} \mathrm{C}$ ) were not substantially contributing to non-specific background. Magnification 20x; scale bar $=100 \mu \mathrm{m}$ 


\subsection{Reduction of lipofuscin autofluorescence}

Lipofuscin is a ubiquitous fluorescent pigment that accumulates with age in long-lived cells, such as neurons and cardiac myocytes (Brizzee et al., 1974). The topographical and temporal patterns of lipofuscin production vary throughout the brain (Mann \& Yates, 1987; Peters et al., 1991). However, the development of lipofuscin generally begins during infancy, from the age of three or four months (Porta, 2002), becomes obvious in human neurons at the age of nine years (Sulzer et al., 2008), and is present in most cortical neurons and glial cells by the age of thirty years (Benavides et al., 2002). This pigment may occupy up to $75 \%$ of the perikaryon of some neurons in the aged brain (Terman \& Brunk, 1998). Lipofuscin in neurons appears to be derived primarily from the breakdown of autophagocytosed mitochondria into a polymer of oxidatively modified protein residues bridged by acid and lipid residues (Terman \& Brunk, 2004, 2006). Mature large lipofuscin granules are found mainly in the perinuclear area but may occasionally be present in the perikaryon, dendrites, axons and even presynaptic areas (Riga et al., 2006).

Under light microscopy, lipofuscin appears yellow-brown or translucent. Under the electron microscope, it appears as a homogeneously dark, irregular mass often containing small lipid droplets, and is surrounded by a single membrane (Harman, 1989). When visualized by a fluorescence or laser-scanning microscope, lipofuscin appears as tiny, punctate intracellular structures that are strongly fluorescent over a wide spectral range (excitation 350-580 nm; emission 400-650 nm). The excitation maximum, about $400 \mathrm{~nm}$, yields a broad emission spectra for lipofuscin granules between 530 and $650 \mathrm{~nm}$, which overlaps with the commonly used fluorophores (Hyden \& Lidstrom, 1950; Eldred et al., 1982; Katz et al., 1984; Porta, 2002; Haralampus-Grynaviski et al., 2003; Double et al., 2008; Figure 1) and thereby interferes with specific immunofluorescent signals. When the fluorescence of antibodyfluorochrome complexes is weak, it is important to unequivocally discriminate between nonspecific (lipofuscin) and specific fluorescence. Four distinct lipofuscin fluorescence spectra have been reported in a sodium dodecyl sulfate extract of rat kidneys: blue fluorescence with excitation/emission maxima at 360/440 nm, respectively, greenish fluorescence at $460 / 530 \mathrm{~nm}$, and yellow fluorescence at 400/620 nm and 580/620 nm. The yellow fluorescence at $400 / 620 \mathrm{~nm}$ accumulates with aging, and its excitation and emission maxima are close to those observed histochemically under a fluorescence microscope (Kikugawa et al., 1997).

Treatment of neural tissue with the lipophilic dye Sudan Black B and $\mathrm{CuSO}_{4}$ have been consistently reported to be useful in quenching the yellow 400/620 nm fluorescence of the lipofuscin to very low levels without substantially affecting the specific fluorescence of the fluorochromes coupled to secondary antibodies (Kikugawa et al., 1997; Brehmer et al., 2004; Schnell et al., 1999; Romijn et al., 1999; Oliveira et al., 2010; Zhang et al., 2010). Moreover, the Autofluorescence Eliminator Reagent from Chemicon International reduces lipofuscin autofluorescence. This reagent consists of a solution of Sudan Black (and possibly other components) in ethanol. One drawback of treating tissues to reduce lipofuscin-related autofluorescence is reduction of the fluorescent signal from the introduced fluorophore. Therefore, it is important to check to what extent the treatment affects the fluorescent signal and choose the method accordingly.

An example of human serial sections of the inferior colliculus treated with Sudan Black B and $\mathrm{CuSO}_{4}$ is shown in Figure 3. Sudan Black B treatment was done according to Kiernan 
(1981), as cited in Romijn et al. (1999), who prescribed dissolving the dye by stirring $0.3 \%$ Sudan Black B in 70\% ethanol at room temperature in the dark for two hours and leaving it standing overnight before filtering it, after which it can be stored in the dark at $4^{\circ} \mathrm{C}$ for at least two months. After immunolabeling the sections, the solution is applied for 10 minutes at room temperature and then the sections are rinsed rapidly eight times in TBS. Another protocol consists of treating the tissue with $\mathrm{CuSO}_{4}$ (Schnell et al., 1999). After immunocytochemistry, the sections are taken out of TBS and dipped briefly in distilled water, followed by treatment with $1 \mathrm{mM} \mathrm{CuSO}_{4}$ in $50 \mathrm{nM}$ ammonium acetate buffer ( $\mathrm{pH}$ 5.0) for 10-30 min, a brief dip in distilled water, and a return to TBS. The samples were coverslipped using $25 \mathrm{mg} / \mathrm{ml}$ DABCO dissolved in Mowiol ${ }^{\mathrm{R}} 4-88$ as mounting media. Application of $\mathrm{CuSO}_{4}$ for 10 minutes after immunohistochemistry substantially reduced tissue autofluorescence while preserving the specific fluorochrome signals. The overall background fluorescence increased substantially when the samples were treated with Sudan Black B, especially when using the 543-nm laser (Figure 3, panel K). The increase in background fluorescence in the samples treated with Sudan Black B could be related to the DABCO antifading agent in the tissue mounting media, as previously observed by Romijn et al., 1999. The commercial product Vectashield and the antifading agent p-phenylenediamine dissolved in glycerol also react similarly (Romijn et al., 1999). If Sudan Black B is used to decrease the lipofuscin-induced autofluorescence, Tris-buffered glycerol at a $\mathrm{pH}$ of 7.0-7.6 (not higher) is recommended as the best mounting medium.

\section{Blocking non-specific binding of antibodies}

The most commonly used method to reduce background staining due to nonimmunological binding of the specific immune sera by hydrophobic interaction is to use a protein blocking solution before application of the primary antibody. The solution should contain proteins similar to those present in the secondary antibody but not resembling those in the primary antibody. Bovine serum albumin (BSA) is probably the most widely used blocking agent for reducing non-specific binding due to hydrophobic interaction, but nonfat dry milk, casein, fish skin gelatin, horse serum and goat serum have also been recommended (Duhamel \& Johnson, 1985; Kaur et al., 2002). However, blocking agents can also cause problems. A decrease in Neurotrace ${ }^{\mathrm{TM}}$ fluorescence has been reported after incubating the samples in the presence of bovine serum albumin, non fat dried milk or horse serum (reported in the manufacturer's web page http://probes.invitrogen.com/ media/pis/mp21480.pdf). An alternative to these reagents is fish skin gelatin. However, in our experience, bovine serum albumin $(3 \%)$ or fish skin gelatin $(2 \%)$ quenched the fluorescence of Neurotrace ${ }^{\mathrm{TM}}$ at $1 / 200$ dilution, which made it necessary to use a higher concentration of Neurotrace ${ }^{\mathrm{TM}}(1 / 100)$ to achieve adequate staining in $20-\mu \mathrm{m}$ sagittal sections of the human inferior colliculus (data not shown). Doubling of the deep-red Neurotrace ${ }^{\mathrm{TM}}$ concentration yielded correct fluorescence staining when blocking was done with BSA or FSG for the deep-red fluorochrome. No substantial differences in fluorescence intensity were observed when BSA or FSG was used for blocking for the other fluorochromes employed, i.e. AF488, AF586, and DAPI (Figure 4). Thus, blocking in a neutral protein solution such as BSA or FSG decreases background of primary and secondary antibodies successfully, but requires a higher concentration of Neurotrace ${ }^{\mathrm{TM}}$ for optimal staining. In previous experiments (data not shown) higher concentrations of blocking proteins also produced increased background staining, so this should be optimized 

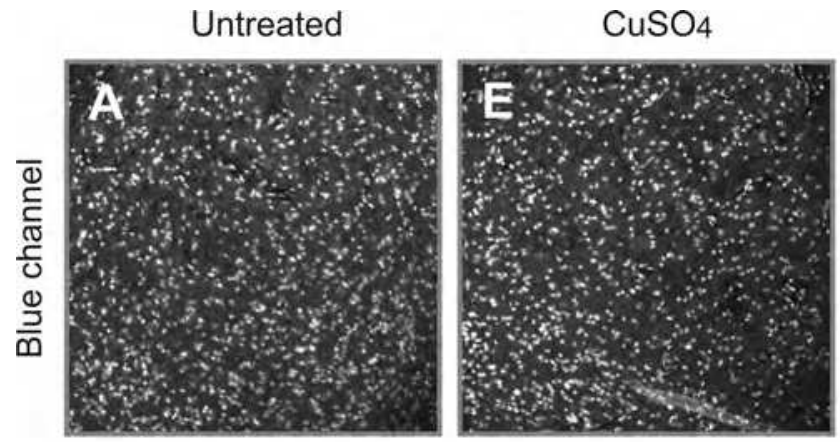

Sudan Black B
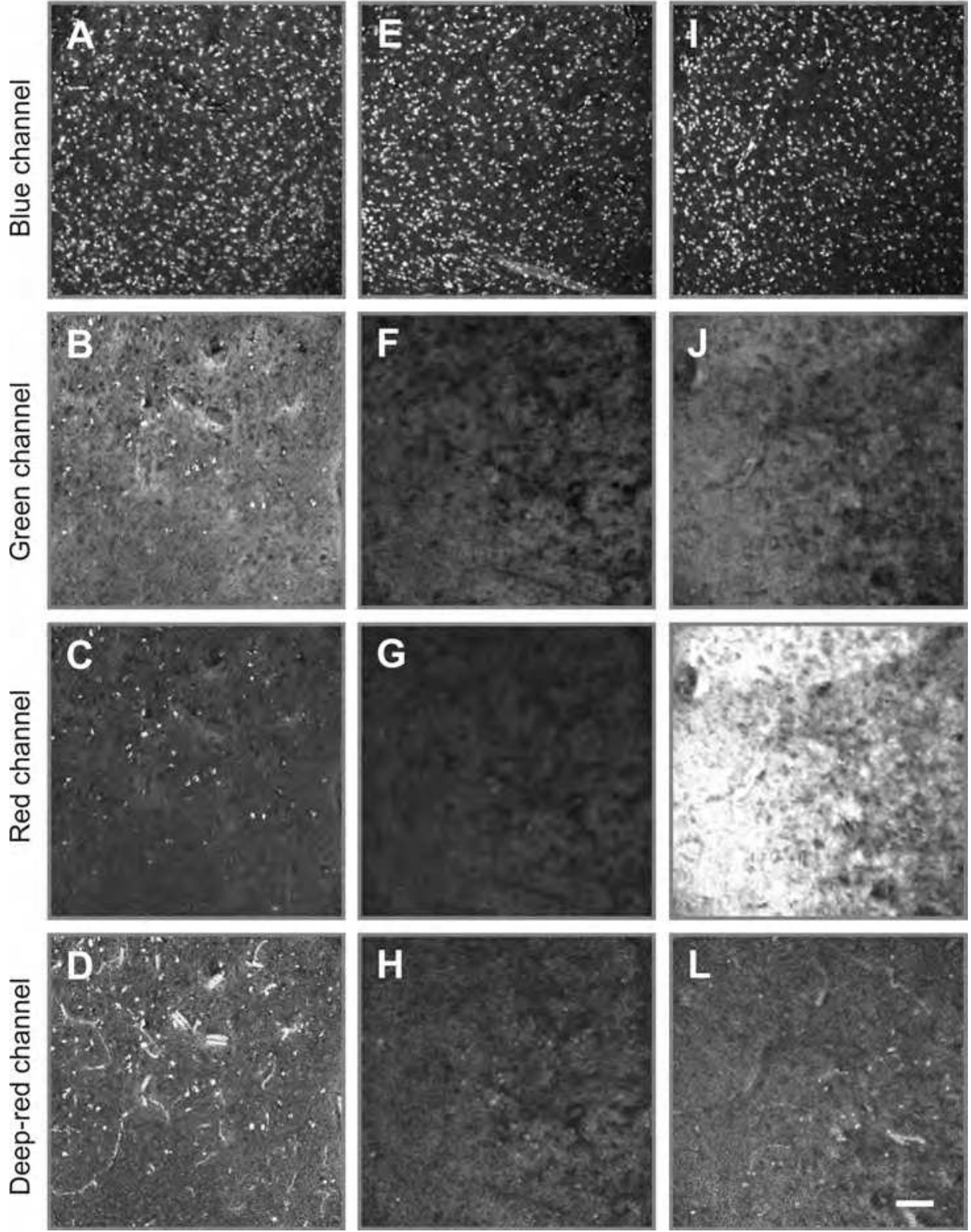

Fig. 3. Lipofuscin autofluorescence in sections of the human inferior colliculus under control conditions (A-D) and after treatment with $1 \mathrm{mM} \mathrm{CuSO}_{4}$ in $50 \mathrm{mM}$ ammonium acetate buffer (pH 5.0) (E-H) or $0.3 \%$ Sudan Black B in 70\% ethanol (I-L) and visualized in the blue (A, E, $\mathrm{I})$, green $(\mathrm{B}, \mathrm{F}, \mathrm{J})$, red $(\mathrm{C}, \mathrm{G}, \mathrm{K})$, and deep-red $(\mathrm{D}, \mathrm{H}, \mathrm{L})$ channels by confocal microscopy. Magnification 20x; scale bar $=100 \mu \mathrm{m}$. 
for different tissue types. In general beginning with $0.5 \%$ blocking protein is recommended and testing higher concentrations if necessary to block non-specific protein absorption.
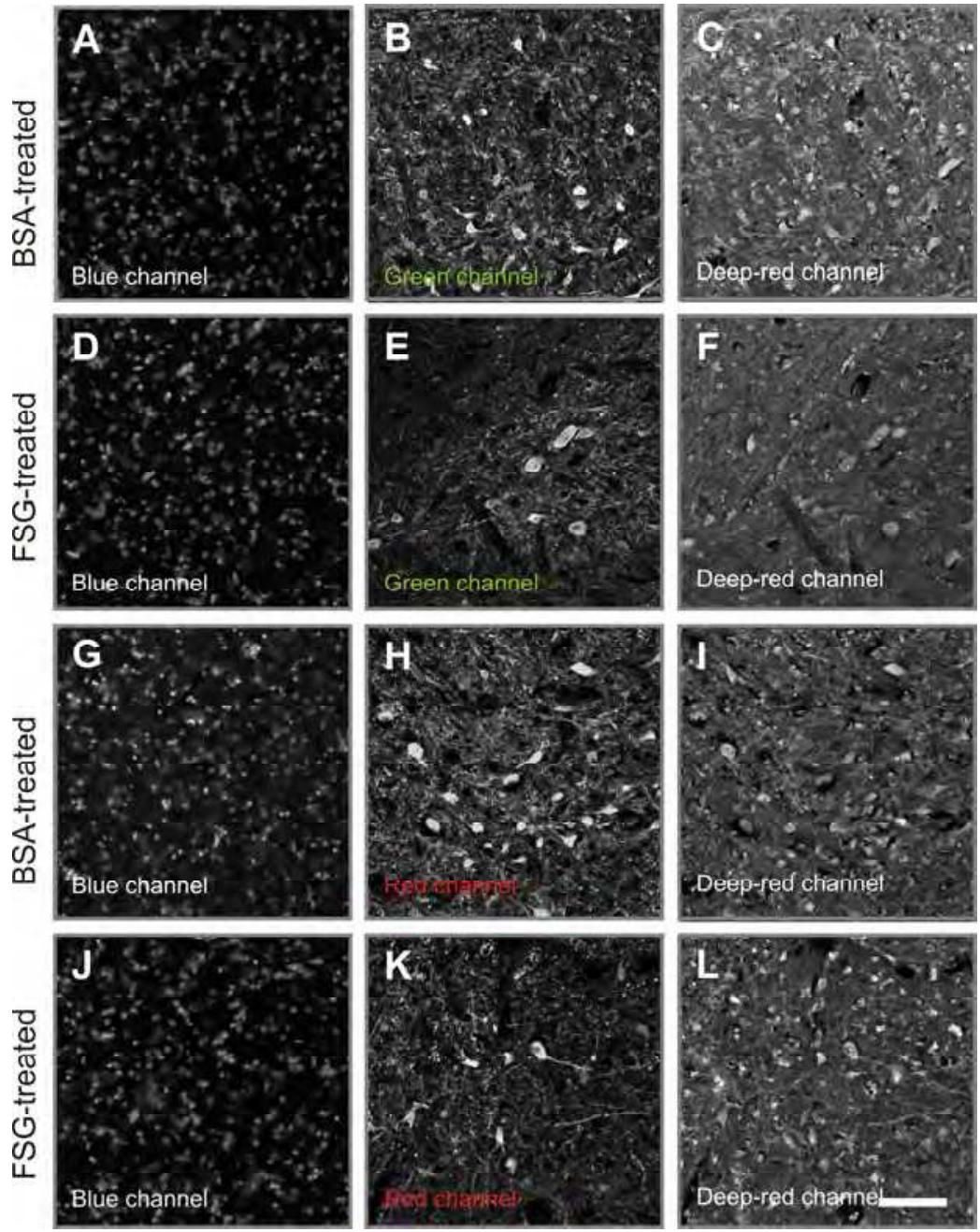

Fig. 4. Effect of bovine serum albumin (BSA) (A-C; G-I) and fish skin gelatin (FSG) (D-F; J$\mathrm{L}$ ) on the fluorescence intensity as visualized by confocal microscopy in the blue (A, D, G, J), green $(B, E)$, red $(\mathrm{H}, \mathrm{K})$, and deep-red $(\mathrm{C}, \mathrm{F}, \mathrm{I}, \mathrm{L})$ channels. The sections were blocked with $2 \%$ BSA or $3 \%$ FSG before incubation with mouse anti-parvalbumin $(2.2 \mu \mathrm{g} / \mathrm{ml}$; P3088, Sigma) and appropriate secondary antibodies labeled with the fluorochrome AlexaFluor 488 (15 $\mu \mathrm{g} / \mathrm{ml}$; A11059, Invitrogen) or AlexaFluor 568 (15 $\mu \mathrm{g} / \mathrm{ml}$; A10037, Invitrogen). The samples were subsequently stained with Neurotrace ${ }^{\mathrm{TM}}$ (1/100 dilution) and DAPI $(1 \mu \mathrm{g} / \mathrm{ml})$. Lipofuscin autofluorescence was then reduced with $\mathrm{CuSO}_{4}$ as previously reported (see section 6.2.). No differences were observed in the intensity of the various fluorochromes when blocked with BSA or FSG. Magnification 20x; scale bar $=100 \mu \mathrm{m}$ 

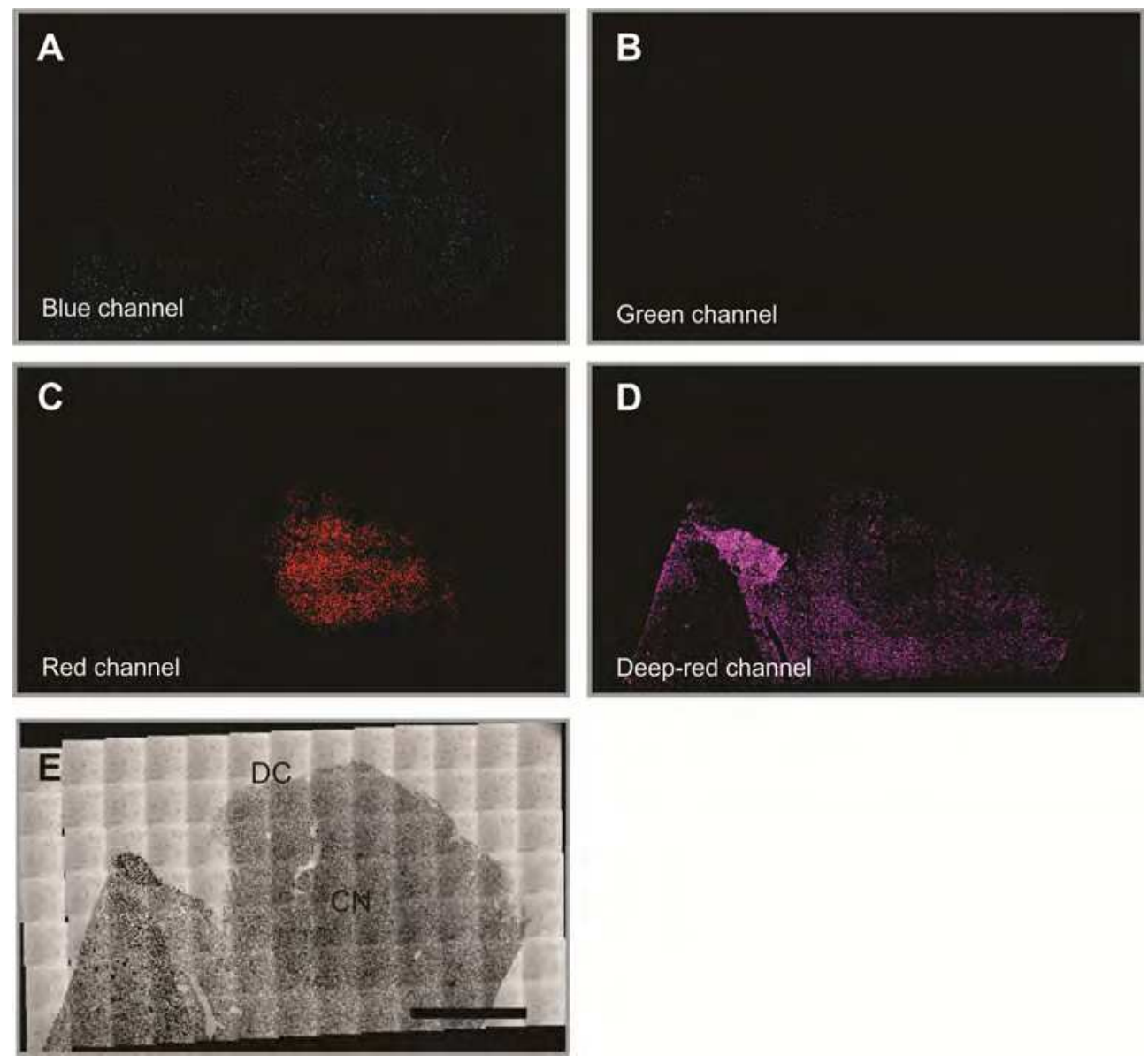

Fig. 5. Two dimensional reconstruction of confocal micrographs of a $20-\mu \mathrm{m}$ sagittal section of the human inferior colliculus. The section was stained for the nuclei with DAPI (A), for calretinin with AlexaFluor 488 (B), for parvalbumin with AlexaFluor 568 (C), and for neurons with deep-red Neurotrace ${ }^{\mathrm{TM}}$ (D). A light microscopy image shows an overview of the inferior colliculus (E). Parvalbumin positive cells are located at the central nucleus (CN) of the inferior colliculus while calretinin positive cells are less abundant and located at the dorsal cortex (DC) as previously reported (Sharma et al., 2009; Tardif et al., 2003). Magnification 20x; bar $=2 \mathrm{~mm}$ 

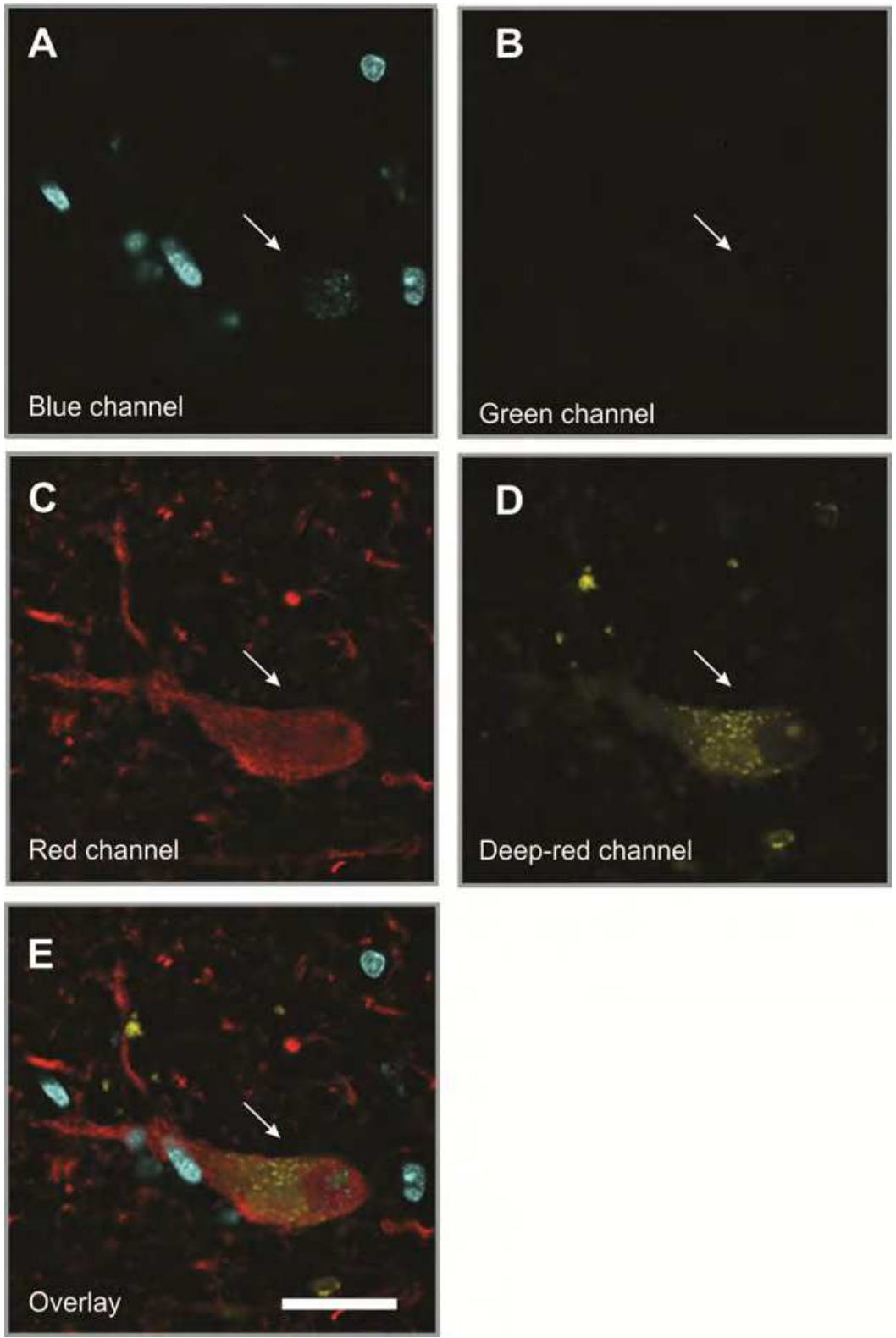

Fig. 6. A parvalbumin positive cell (arrow) located at the central nucleus of the human inferior colliculus visualized by confocal microscopy. The $20-\mu \mathrm{m}$ sagittal section of the human inferior colliculus was stained for the nuclei with DAPI (A), for calretinin with AlexaFluor 488 (B), for parvalbumin with AlexaFluor 568 (C), and for neurons with deepred Neurotrace ${ }^{\mathrm{TM}}$ (D). Panel E shows the overlay of panels A, B, C and D. Magnification 63x; bar $=20 \mu \mathrm{m}$ 

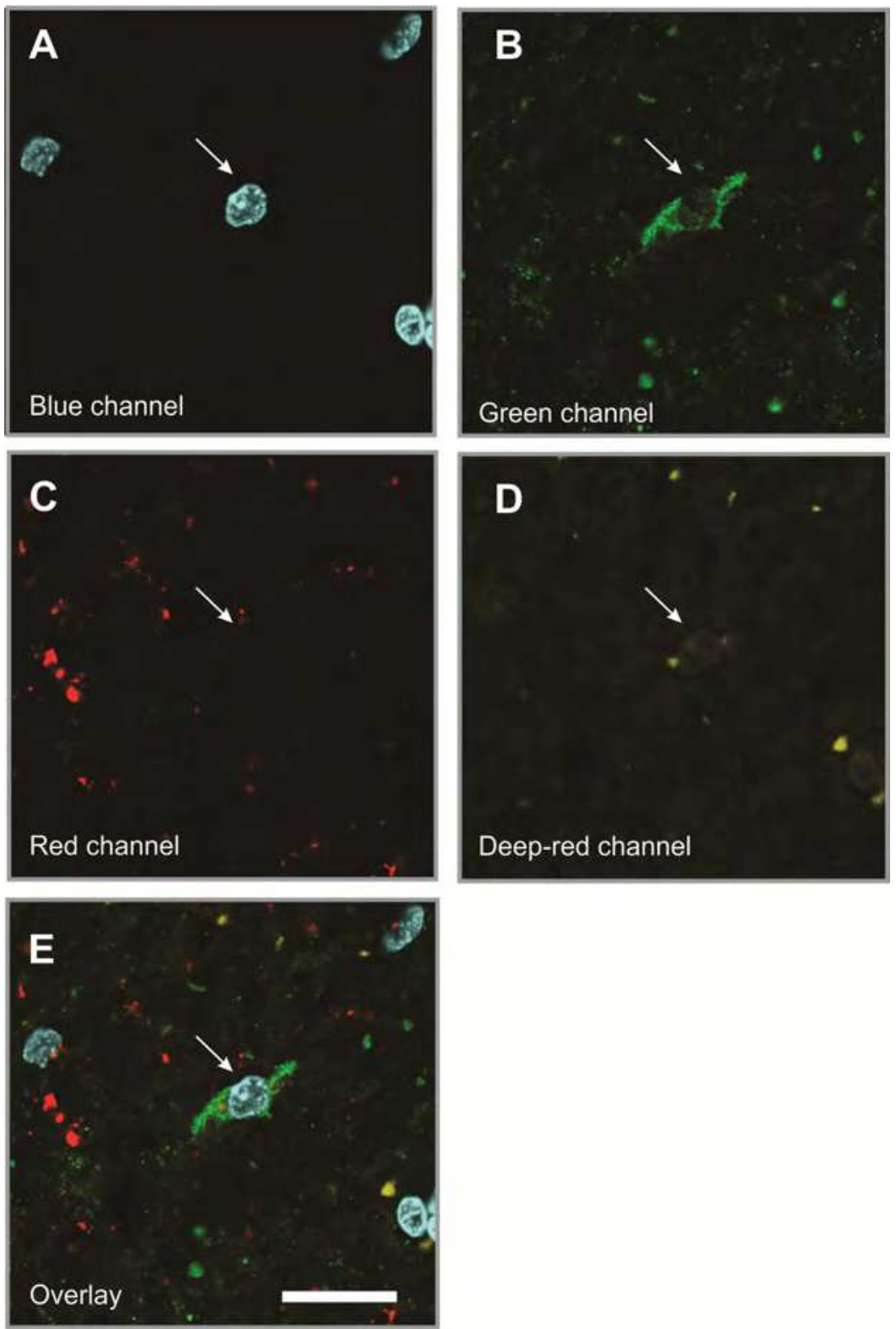

Fig. 7. A calretinin positive cell (arrow) located at the dorsal cortex of the human inferior colliculus visualized by confocal microscopy. The $20-\mu \mathrm{m}$ sagittal section of the human inferior colliculus was stained for the nuclei with DAPI (A), for calretinin with AlexaFluor 488 (B), for parvalbumin with AlexaFluor 568 (C), and for neurons with deep-red Neurotrace ${ }^{\mathrm{TM}}(\mathrm{D})$. Panel E shows the overlay of panels A, B, C and D. Magnification 63x; bar $=20 \mu \mathrm{m}$. 


\section{Basic protocol for multiple immunostaining of neural tissue}

- Obtain human brain tissue as quickly as possible after death (less than one day is preferred).

- $\quad$ Fix the tissue with freshly prepared $4 \%$ paraformaldehyde in phosphate buffered saline (PBS; pH 7.4) for not more than two weeks at $4^{\circ} \mathrm{C}$ in the dark. Refresh the fixative every three days. Overnight fixation for small $\left(<1 \mathrm{~cm}^{3}\right)$ tissue pieces is sufficient. Freshness of the fixative and the incubation conditions are of great importance to avoid autofluorescence.

- Immerse the tissue in $10 \%$ sucrose in PBS (pH 7.4) at $4^{\circ} \mathrm{C}$ until the tissue sinks. Repeat the procedure with $20 \%$ sucrose and then with $30 \%$ sucrose.

- Freeze the tissue in a cryo-embedding medium such as OCT and store it in an air tight container at $-80^{\circ} \mathrm{C}$.

- At least one hour before sectioning, equilibrate the tissue blocks at $-20^{\circ} \mathrm{C}$. Sections are cut, rehydrated and washed in Tris buffered saline (TBS) for at least 40 minutes immediately before any treatment. TBS is used for all washes and dilutions, but other buffers such as PBS may also be used. To minimize autofluorescence, make the sections as thin as possible; i.e. 15-20 $\mu \mathrm{m}$. Wash the floating sections in TBS for $3 \times 5$ minutes.

- $\quad$ Permeabilize the sections by immersion in $0.5 \%$ Triton X-100 in TBS for 30 min at $4^{\circ} \mathrm{C}$ in the dark. Wash the floating sections in TBS for $3 \times 5$ minutes.

- For blocking, incubate the sections in a mixture of $0.5 \%$ serum from the species that the secondary antibody is originated from and $1 \%$ fish skin gelatin (or $0.5 \%$ BSA) in TBS for one hour at room temperature.

- To reduce fixative-induced autofluorescence, if necessary, pretreat the fixed sections with $1 \% \mathrm{NaBH}_{4}$ in PBS for 10-20 min, or $50 \mathrm{mM} \mathrm{NH}_{4} \mathrm{Cl}$ in PBS for 5-10 min, or 100-300 $\mathrm{mM}$ glycine in TBS or PBS pH 7.4 for one or two hours at $4^{\circ} \mathrm{C}$. If the tissue is fragile, it is better to use glycine.

- Blot excess blocking solution from sections and incubate overnight at $4^{\circ} \mathrm{C}$ with a mixture of appropriately diluted primary antibodies in TBS containing $1 \%$ FSG (or $0.5 \%$ BSA).

- Wash sections in 1\% FSG (or 0.5\% BSA) in TBS for 4x15 min. Incubate sections overnight at $4^{\circ} \mathrm{C}$ with a mixture of fluorophore-conjugated secondary antibodies raised against the corresponding species of primary antibodies in 1\% FSG (or 0.5\% BSA). Adding $0.5 \%$ Tween-20 into the secondary antibody dilution aids to reduce nonspecific staining (Sun et al., 2009). Wash sections in TBS for $4 \times 15 \mathrm{~min}$.

- Counterstain neurons if necessary, e.g. with 1/100 dilution of deep-red NeurotraceTM (Invitrogen), for $30 \mathrm{~min}$ at room temperature followed by rinsing for $2 \mathrm{~h}$ in TBS. Then, counterstain nuclei if necessary, e.g., with $1 \mu \mathrm{g} / \mathrm{ml}$ DAPI in TBS for 3 min at room temperature. Wash sections in TBS for $3 \times 5 \mathrm{~min}$.

- $\quad$ Reduce lipofuscin-induced autofluorescence by rinsing briefly with distilled water, then incubating the samples for 10-60 min with a solution of $1 \mathrm{mM} \mathrm{CuSO}_{4}$ in $50 \mathrm{mM}$ ammonium acetate buffer ( $\mathrm{pH} 5$ ). Rinse quickly in distilled water and wash eight times in TBS. Alternatively, the samples can be treated for 10 min with $0.3 \%$ Sudan Black B in $70 \%$ ethanol.

- Place the sections on a slide and mount with a mixture of glycerol/PBS $(9: 1, \mathrm{v} / \mathrm{v})$ supplemented with an antifading agent, e.g. $25 \mathrm{mg} / \mathrm{ml}$ 1,4-diaza-bicyclo[2.2.2]octane 
(DABCO) or $0.5 \%$ n-propylgallate $(\mathrm{pH} 7.4)$. Do not use anti-fade mounting media on samples treated with Sudan Black B.

- An example of human brain tissue multi-labeled as described in this section is shown in Figures 5-7. Briefly, the inferior colliculi were fixed with $4 \%$ paraformaldehyde, sectioned at $20 \mu \mathrm{m}$, incubated in a pooled primary antibody solution containing mouse anti-parvalbumin monoclonal antibody $(2.2 \mu \mathrm{g} / \mathrm{ml} ;$ P3088, Sigma-Aldrich, Bornem, Belgium) and rabbit anti-calretinin polyclonal antibody $(0.8 \mu \mathrm{g} / \mathrm{ml}$; C7479, SigmaAldrich) diluted in 1\% FSG, followed by incubation in AlexaFluor 488 donkey-antimouse and AlexaFluor 568 donkey anti-rabbit from Invitrogen $(15 \mu \mathrm{g} / \mathrm{ml})$. The figures also show samples counterstained with deep-red Neurotrace ${ }^{\mathrm{TM}}$ (1/100 dilution) and DAPI $(1 \mu \mathrm{g} / \mathrm{ml})$ before treatment with $\mathrm{CuSO}_{4}$ for 10 minutes as described in this section. While lipofuscin-induced autofluorescence is no longer observed in the blue, green and red channel, it is still an issue in the deep-red channel. The remaining autofluorescence in the deep-red channel is possibly related to the weak fluorescent signal detected upon staining with deep-red Neurotrace ${ }^{\mathrm{TM}}$, especially in small neurons of the dorsal cortex.

\section{Conclusion}

In this chapter we discuss multiple-label fluorescence confocal microscopy and methods to reduce autofluorescence in sections of the human central nervous system. We also evaluate the quenching of fluorescence by non-specific protein adsorption. We conclude that treatment of neural tissues with reagents to reduce endogenous autofluorescence is helpful in improving specific signal-to-noise ratios. Sections processed in this way are suitable for examining the complex structure and organization of human brain tissue.

\section{Acknowledgments}

The authors thank Prof. Piette and Prof. Cuvelier (Forensic Institute and Department of Pathology, respectively, University of Ghent, Belgium), for providing the human inferior colliculi. They also acknowledge Dr. Amin Bredan for editing, Barbara De Bondt, Dominique Jacobus, and Stefanie Mortier for technical assistance with the immunohistological sections and Eef Parthoens and Evelien Van Hamme (VIB-DMBR microscopy core facility) for technical assistance with the Leica confocal microscope and image processing.

\section{References}

Benavides, S.H.; Monserrat, A.J.; Farina, S. \& Porta, E.A. (2002). Sequential histochemical studies of neuronal lipofuscin in the human cerebral cortex from the first to the ninth decade of life. Archives of Gerontology and Geriatrics, Vol. 34, No. 3, (May -June 2002), pp. 219-231, ISSN 0167-4943

Beisker, W.; Dolbeare, F. \& Gray J.W. (1987) An improved immunocytochemical procedure for high-sensitivity detection of incorporated bromodeoxyuridine. Cytometry, Vol. 8, No. 2 (March 1987), pp. 235-239, ISSN 1552-4922 
Bratthauer, G.L. (2010) The avidin-biotin complex (ABC) method and other avidin-biotin binding methods. Methods in Molecular Biology, Vol. 588, pp. 257-270, ISSN 10643745

Brehmer, A.; Blaser, B.; Seitz, G.; Schrödl, F. \& Neuhuber, W. (2004). Pattern of lipofuscin pigmentation in nitrergic and non-nitrergic, neurofilament immunoreactive myenteric neuron types of human small intestine. Histochemistry and Cell Biology, Vol. 121, No. 1, (January 2004), pp. 13-20, ISSN 0948-6143

Brizzee, K.R.; Ordy, J.M. \& Kaack, B. (1974). Early appearance and regional differences in intraneuronal and extraneuronal lipofuscin accumulation with age in the brain of a nonhuman primate (Macaca mulatta). Journal of Gerontology, Vol. 29, No. 4, (July 1974), pp. 366-381, ISSN 0022-1422

Brouns, I.; Van Nassauw, L.; Van Genechten, J.; Majewski, M.; Scheuermann, D.W.; Timmermans, J.P. \& Adriaensen, D. (2002). Triple immunofluorescence staining with antibodies raised in the same species to study the complex innervation pattern of intrapulmonary chemoreceptors. Journal of Histochemistry and Cytochemistry, Vol. 50, No. 4, (April 2002), pp. 575-582, ISSN 0022-1554

Buchwalow, I.B.; Minin, E.A. \& Boecker, W. (2005). A multicolor fluorescence immunostaining technique for simultaneous antigen targeting. Acta Histochemica Vol 107, No. 2, (July 2005), pp. 143-148, ISSN 0065-1281

Callis, G. (2010). Glutaraldehyde-induced autofluorescence. Biotechnic and Histochemistry, Vol. 85, No. 4, (August 2010), pp. 269, ISNN 1052-0295

Clancy, B. \& Cauller, L.J. (1998). Reduction of background autofluorescence in brain sections following immersion in sodium borohydride. Journal of Neuroscience Methods, Vol. 83, No. 2, (September 1998), pp. 97-102, ISNN 0165-0270

Collins, J.S. \& Goldsmith, T.H. (1981) Spectral properties of fluorescence induced by glutaraldehyde fixation. Journal of Histochemistry and Cytochemistry, Vol. 29, No. 3, (March 1981), pp. 411-414, ISNN 0022-1554

Dailey, M.; Marrs, G.; Satz, J. \& Waite, M. (1999). Exploring biological structure and function with confocal microscopy. Biological Bulletin, Vol. 197, No. 2, (October 1999), pp. 115-122, ISSN 0006-3185

De Groot, C.J.; Theeuwes, J.W.; Dijkstra, C.D. \& van der Valk, P. (1995). Postmortem delay effects on neuroglial cells and brain macrophages from Lewis rats with acute experimental allergic encephalomyelitis: an immunohistochemical and cytochemical study. Journal of Neuroimmunology, Vol. 59, No. 1-2, (June 1995), pp. 123-134, ISSN 0165-5728

Del Castillo, P.; Llorente, A.R. \& Stockert, J.C. (1989). Influence of fixation, exciting light and section thickness on the primary fluorescence of samples for microfluorometric analysis. Basic and Applied Histochemistry, Vol. 33, No. 3, pp. 251-257, ISSN 03917258

Double, K.L.; Dedov, V.N.; Fedorow, H.; Kettle, E.; Halliday, G.M.; Garner, B. \& Brunk, U.T. (2008). The comparative biology of neuromelanin and lipofuscin in the human brain. Cellular and Molecular Life Sciences, Vol. 65, No. 11, (February 2008), pp. 16691682, ISSN 1420-682X 
Duhamel, R.C. \& Johnson, D.A. (1985) Use of nonfat dry milk to block nonspecific nuclear and membrane staining by avidin conjugates. Journal of Histochemistry and Cytochemistry, Vol. 33, No. 7, (July 1985), pp. 711-714, ISSN 0022-1554

Eldred, G.E.; Miller, G.V.; Stark, W. \& Feeney-Burns, L. (1982). Lipofuscin: resolution of discrepant fluorescent data. Science, Vol. 216, No. 4547, (May 1982), pp. 757-759, ISSN 0036-8075

Fodor, M.; van Leeuwen, F.W. \& Swaab, D.F. (2002). Differences in postmortem stability of sex steroid receptor immunoreactivity in rat brain. The Journal of Histochemistry and Cytochemistry, Vol. 50, No. 5, (May 2002), pp. 641-650, ISSN 0022-1554

Fox, C.H.; Johnson, F.B.; Whiting, J. \& Roller, P.P. (1985). Formaldehyde fixation. The Journal of Histochemistry and Cytochemistry, Vol. 33, No. 8, (Augustus 1985), pp. 845-853, ISSN 0022-1554

Frisch, J.; Houchins, J.P.; Grahek, M.; Schoephoerster, J.; Hagen, J.; Sweet, J.; Mendoza, L.; Schwartz, D. \& Kalyuzhny, A.E. (2011) Novel multicolor immunofluorescence technique using primary antibodies raised in the same host species. In: Signal Transduction Immunohistochemistry: Methods and Protocols, Methods in Molecular Biology, A.E. Kalyuzhny, (Ed.), Vol. 717, No. 4, pp. 233-244 ISSN 1064-3745 e-ISSN 1940-6029 ISBN 978-1-61779-023-2 e-ISBN 978-1-61779024-9

Haralampus-Grynaviski, N.M.; Lamb, L.E.; Clancy, C.M.R.; Skumatz, C.; Burke, J.M.; Sarna, T. \& Simon, J.D. (2003). Spectroscopic and morphological studies of human retinal lipofuscin granules. Proceedings of the National Academy of Sciences of the United States of America, Vol.100, No. 6, (March 2003), pp. 3179-3184, ISSN 0027-8424

Harman, D. (1989) Lipofuscin and ceroid formation: the cellular recycling system. Advances in Experimental Medicine and Biology, Vol. 266, pp. 3-15, ISSN 0065-2598

Hilbig, H.; Bidmon, H.J.; Oppermann, O.T. \& Remmerbach, T. (2004). Influence of postmortem delay and storage temperature on the immunohistochemical detection of antigens in the CNS of mice. Experimental and Toxicologic Pathology, Vol. 56, No. 3, (December 2004), pp. 159-171, ISSN 0940-2993

Hyden, H. \& Lindstrom, B. (1950). Microspectrographic studies on the yellow pigment in nerve cells. Discussions of the Faraday Society, Vol. 9, (January 1950), pp. 436-441, ISSN 0014-7664

Katz, M.L.; Robinson, W.G.; Herrmann, R.K.; Groome, A.B. \& Bieri, J.G. (1984). Lipofuscin accumulation resulting from senescence and vitamin E deficiency: spectral properties and tissue distribution. Mechanisms of Ageing and Development, Vol. 25, No. 1-2 , (April-May 1984), pp. 149-159, ISSN 0047-6374

Kaur, R.; Dikshit, K.L. \& Raje M. (2002). Optimization of immunogold labeling TEM: an ELISA-based method for evaluation of blocking agents for quantitative detection of antigen. Journal of Histochemistry and Cytochemistry, Vol. 50, No. 6, June 2002), pp. 863-873, ISSN ISSN 0022-1554

Kikugawa, K.; Beppu, M.; Sato, A. \& Kasai, H. (1997). Separation of multiple yellow fluorescent lipofuscin components in rat kidney and their characterization. 
Mechanisms of Ageing and Development, Vol. 97, No. 2, (August 1997), pp. 93-107, ISSN 0047-6374

Mann, D.M.A. \& Yates, P.O. (1987). Ageing, nucleic acids and pigments, In: Recent advances in Neuropathology, Cavanagh, J.B., pp. 109-137, Livingston, ISBN 9780443032264, Edinburgh.

Martin, P.M. \& O'Callaghan, J.P. (1995). A direct comparison of GFAP immunocytochemistry and GFAP concentration in various regions of ethanol-fixed rat and mouse brain. Journal of Neuroscience Methods, Vol. 58, No. (1-2), (May 1995), pp. 181-192, ISSN 0165-0270

McKee, A.C. (1999). Brain banking: basic science methods. Alzheimer Disease and Associated Disorders, Vol. 13, No. Suppl 1, (April-June 1999), pp. S39-44, ISSN 0893-0341

Ngwenya, L.B.; Peters, A. \& Rosene, D.L. (2005). Light and electron microscopic immunohistochemical detection of bromodeoxyuridine-labeled cells in the brain: different fixation and processing protocols. The Journal of Histochemistry and Cytochemistry, Vol. 53, No. 7, (July 2005), pp. 821-832, ISSN 0022-1554

Oliveira, V.C.; Carrara, R.C.V.; Simoes, D.L.C.; Saggioro, F.P.; Carlotti, C.G. Jr.; Covas, D.T. \& Neder, L. (2010). Sudan Black B treatment reduces autofluorescence and improves resolution of in situ hybridization specific fluorescent signals of brain sections. Cellular and Molecular Biology, Vol. 25, No. 8, (August 2010), pp. 1017-1024, ISSN 0006-3088

Peters, A.; Palay, S.L. \& Webster, H.D. (1991). The fine structure of the nervous system ( $3^{\text {rd }}$ ed.), Oxfort University Press, ISBN 0195065719, New York.

Porta, E.A. (2002) Pigments in aging: an overview. Annals of the New York Academy of Sciences, Vol. 959 , No. 1, (January 2002), pp. 57-65, ISSN 0077-8923

Ravid, R. \& Grinberg, L.T. (2008). How to run a brain bank--revisited. Cell Tissue Bank, Vol. 9, No. 3, (September 2008), pp. 149-150, ISSN 1389-9333

Riga, D.; Riga, S.; Halalau, F. \& Schneider, F. (2006). Brain lipopigment accumulation on normal and pathological aging. Annals of the New York Academy of Sciences, Vol. 1067, No. 1, (May 2006), pp. 158-163, ISSN 0077-8923

Romijn, H.J.; van Uum, J.F.M.; Breedijk, I.; Emmering, J.; Radu, I. \& Pool, C.W. (1999). Double immunolabeling of neuropeptides in the human hypothalamus as analyzed by confocal laser scanning fluorescence microscopy. Journal of Histochemistry and Cytochemistry, Vol. 47, No. 2, (February 1999), pp. 229-236, ISSN 0022-1554

Schnell, S.A.; Staines, W. \& Wessendorf, M.W. (1999). Reduction of lipofuscin-like autofluorescence in fluorescently labeled tissue. Journal of Histochemistry and Cytochemistry, Vol. 47, No. 6, (June 1999), pp. 719-730, ISSN 0022-1554

Selever, J.; Kong, J.Q. \& Arenkiel, B.R. (2011). A rapid approach to high-resolution fluorescence imaging in semi-thick brain slices. Journal of Visualized Experiments, Vol. 26, No. 53, (July 2011), pii. 2807, ISSN 1940-087X

Sharma, V.; Nag, T.C.; Wadhwa, S. \& Roy T.S. (2009). Stereological investigation and expression of calcium-binding proteins in developing human inferior colliculus. Journal of Chemical Neuroanatomy, Vol. 37, No. 2, (March 2009), pp. 78-86, ISSN 08910618 
Sulzer, D.; Mosharov, E.; Talloczy, Z.; Zucca, F.A.; Simon, J.D. \& Zecca, L. (2008). Neuronal pigmented autophagic vacuoles: lipofuscin, neuromelanin, and ceroid as macroautophagic responses during aging and disease. Journal of Neurochemistry, Vol. 106, No. 1, (July 2008), pp. 24-36, ISSN 1471-4159

Sun, A.; Liu, M. \& Bing, G. (2009). Improving the specificity of immunological detection in aged human brain tissue samples. Internal Journal of Physiology, Pathophysiology and Pharmacology, Vol. 2, No. 1, (Dec 2009), pp. 29-35, ISSN 1944-8171

Tagliaferro, P.; Tandler, C.J.; Ramos, A.J.; Saavedra, J.P. \& Brusco, A. (1997). Immunofluorescence and glutaraldehyde fixation. A new proceure based on the Schiff-quenching method. Journal of Neuroscience Methods, Vol. 77, No. 2, (December 1997), pp.191-197, ISSN 0165-0270

Tardif, E.; Chiry, O.; Probst, A.; Magistretti, P.J. \& Clarke, S. 2003. Patterns of calcium binding proteins in the human inferior colliculus: identification of subdivisions and evidence for putative parallel systems. Neuroscience, Vol. 116, No. 4, pp. 1111-1121, ISSN 0306-4522

Terman, A. \& Brunk, U.T. (1998). Lipofuscin: mechanisms of formation and increase with aging. Acta Pathologica, Microbiologica et Immunologica Scandinavica, Vol. 106, No. 2, (February 1998), pp. 265-276, ISSN 09034641

Terman, A. \& Brunk, U. (2004). Lipofuscin. International Journal of Biochemistry and Cell Biology, Vol. 36, No. 8, (August 2004), pp. 1400-1404, ISSN 1357-2725

Terman, A. \& Brunk, U. (2006). Oxidative stress, accumulation of biological "garbage" and aging. Antioxidants and Redox Signaling, Vol. 8, No. 1-2, (January-February 2006), pp. 197-204, ISSN 1523-0864

Tokuyasu, K.T. (1973). A technique for ultracryotomy of cell suspensions and tissues. Journal of Cell Biology, Vol. 57, No. 2, (May 1973), pp. 551-565, ISNN 0021-9525

Tóth, Z.E. \& Mezey, E. (2007). Simultaneous visualization of multiple antigens with tyramide signal amplification using antibodies from the same species. Journal of Histochemistry and Cytochemistry, Vol. 55, No. 6, (June 2007), pp. 545-554, ISSN 00221554

Waldvogel, H.J.; Bullock, J.Y.; Synek, B.J.; Curtis, M.A.; van Roon-Mom, W.M. \& Faull, R.L. (2008). The collection and processing of human brain tissue for research. Cell Tissue Bank, Vol. 9, No. 3, (September 2008), pp. 169-179, ISSN 1389-9333

Waldvogel, H.J.; Curtis, M.A.; Baer, K.; Rees, M.I. \& Faull, R.L. (2006). Immunohistochemical staining of post-mortem adult human brain sections. Nature Protocols, Vol. 1, No. 6, pp. 2719-2732, ISSN 1754-2189

Willingham, M.C. (1983). An alternative fixation-processing method for pre-embedding ultrastructural immunocytochemistry of cytoplasmic antigens: the GBS (glutaraldehyde-borohydride-saponin) procedure. Journal of Histochemistry and Cytochemistry, Vol. 31, No. 6, (June 1983), pp.791-798, ISSN 0022-1554

Willingham, M.C. (1999). Chapter 17 Fluorescence labeling of intracellular antigens of attached or suspended tissue-cultured cells. In: Methods in Molecular BiologyTM, Series: Methods in Molecular Biology, LC Javois (Ed.), Vol. 115., pp. 121-130, Humana Press Inc, ISBN 0-89603-570-0 II, Totowa, NJ 
Zhang, Y.; Zhang, W.; Johnston, A.H.; Newman, T.A.; Pyykkö, I. \& Zou, J. (2010). Improving the visualization of fluorescently tagged nanoparticles and fluorophore-labeled molecular probes by treatment with $\mathrm{CuSO}_{4}$ to quench autofluorescence in the rat inner ear. Hearing Research, Vol. 269, No. 1-2, (October 2010), pp. 1-11, ISSN 03785955 


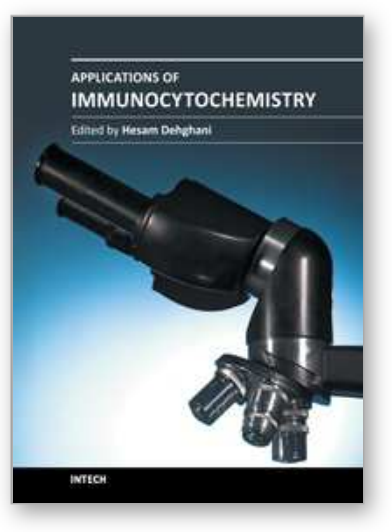

\author{
Applications of Immunocytochemistry \\ Edited by Dr. Hesam Dehghani
}

ISBN 978-953-51-0229-8

Hard cover, 320 pages

Publisher InTech

Published online 09, March, 2012

Published in print edition March, 2012

Immunocytochemistry is classically defined as a procedure to detect antigens in cellular contexts using antibodies. However, over the years many aspects of this procedure have evolved within a plethora of experimental setups. There are different ways to prepare a given specimen, different kinds of antibodies to apply, different techniques for imaging, and different methods of analyzing the data. In this book, various ways of performing each individual step of immunocytochemistry in different cellular contexts are exemplified and discussed. Applications of Immunocytochemistry offers technical and background information on different steps of immunocytochemistry and presents the application of this technique and its adaptations in cell lines, neural tissue, pancreatic tissue, sputum cells, sperm cells, preimplantation embryo, arabidopsis, fish gonads, and Leishmania.

\title{
How to reference
}

In order to correctly reference this scholarly work, feel free to copy and paste the following:

Araceli Diez-Fraile, Nico Van Hecke, Christopher J. Guérin and Katharina D’Herde (2012). Optimizing Multiple Immunostaining of Neural Tissue, Applications of Immunocytochemistry, Dr. Hesam Dehghani (Ed.), ISBN: 978-953-51-0229-8, InTech, Available from: http://www.intechopen.com/books/applications-ofimmunocytochemistry/optimizing-multiple-immunostaining-of-neural-tissue

\section{INTECH}

open science | open minds

\author{
InTech Europe \\ University Campus STeP Ri \\ Slavka Krautzeka 83/A \\ 51000 Rijeka, Croatia \\ Phone: +385 (51) 770447 \\ Fax: +385 (51) 686166 \\ www.intechopen.com
}

\author{
InTech China \\ Unit 405, Office Block, Hotel Equatorial Shanghai \\ No.65, Yan An Road (West), Shanghai, 200040, China \\ 中国上海市延安西路65号上海国际贵都大饭店办公楼405单元 \\ Phone: +86-21-62489820 \\ Fax: +86-21-62489821
}


(C) 2012 The Author(s). Licensee IntechOpen. This is an open access article distributed under the terms of the Creative Commons Attribution 3.0 License, which permits unrestricted use, distribution, and reproduction in any medium, provided the original work is properly cited. 